\title{
Charla con Alberto Prieto Arciniega
}

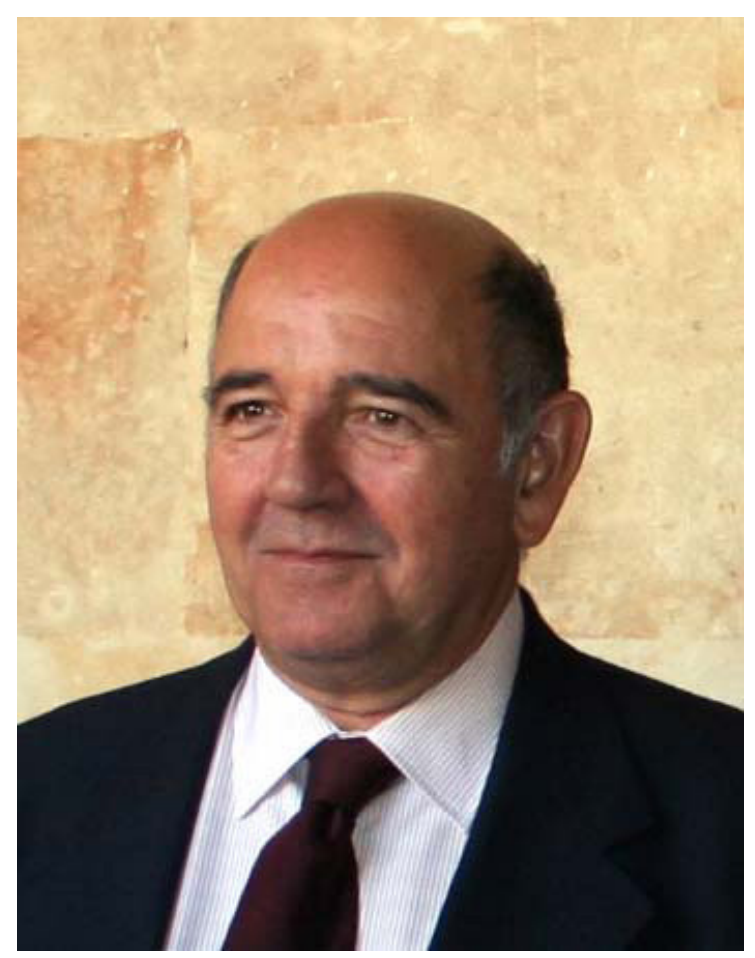

Alberto Prieto Arciniega estudió en la Universidad de Granada, de la que fue profesor y donde realizó su tesis doctoral bajo la dirección de Marcelo Vigil Pascual. Desde 1977 ha sido profesor en la Universidad Autónoma de Barcelona, en la que recientemente se ha jubilado como catedrático. Sirva esta breve entrevista como un modesto reconocimiento más entre los muchos y merecidos que ha recibido por su fructífera e infatigable carrera científica.

El profesor Prieto ha compaginado su trabajo docente con una intensa labor de edición y de investigación, pudiendo destacar entre sus líneas el estudio de la organización territorial de la Hispania Romana, del paisaje, de las diversas formas de dependencia en el mundo antiguo, y de las formas de difusión de la historia a través del cine como instrumento de transformación y conocimiento. Su producción con respecto al cine es amplísima, cabiendo mencionar los volúmenes recopilatorios La Antigüedad filmada (Madrid, Ediciones Clásicas, 2004) y La Antigüedad a través del cine (Barcelona, Universidad de Barcelona, 2010). 
Iván Pérez Miranda, El Futuro del Pasado (FdP): Antes de nada nos gustaría expresarle nuestro agradecimiento por permitirnos realizar esta entrevista. Para comenzar, desde su punto de vista, ¿qué cree que ha mejorado y qué ha empeorado en la investigación y enseñanza de la Historia en los últimos años?

Alberto Prieto Arciniega (AP): Ha mejorado la búsqueda de información, pero en muchos casos suele ser caótica, pues no se sabe separar lo más importante de lo superficial. En otro sentido, cada vez se concede menos importancia a las causas y consecuencia de los hechos históricos como a una rigurosa comprobación de la información existente acompañada de una sólida revisión de las fuentes existentes.

FdP: Este año hemos dedicado la sección monográfica de la revista a reflexionar sobre Cine e Historia, un tema que usted conoce bien. Creo que coincidiremos en que el cine puede ser una potente herramienta para la difusión y de transformación, pero ¿cree que los historiadores le prestamos suficiente atención a formas de comunicación como el cine (u otras como la televisión, o la literatura) y al impacto que pueden tener en la transformación de la concepción del pasado por parte de la sociedad?

AP: Creo que la postura dominante es rechazarlo como no correcto, pero por desgracia al igual que la novela histórica cada vez tienen más seguidores porque su mensaje es muy simple y no hace falta pensar mucho y a la vez el público se autoengańa creyendo que sabe mucha historia; por ejemplo hay personas que se creen todo lo que han visto en novelas y películas como El código Da Vinci por ejemplo.

Los medios de comunicación dominantes potencian una visión plana del pasado que aleja la historia del presente y ese fenómeno va a más, ya que cualquiera se cree que sabe y frente a ello solo cabe defender siempre el oficio del historiador como algo que apasione al público aunque en el actual momento que estamos viviendo la defensa de valores como el esfuerzo o que las cosas no son blancas o negras o que el héroe no es el único protagonista de la historia.

Se ha dicho que en la tragedia ateniense el héroe es el gran derrotado y el protagonismo lo tiene el demos tanto en la política como en las gradas como público.

FdP: Desde los inicios del presente siglo parece que el mundo antiguo, olvidado en cierta medida desde la crisis del peplum, ha vuelto a tener presencia en la gran pantalla como fuente de inspiración. Desde Gladiator (2000), Hollywood parece haber recuperado el interés 
por la antigüedad, tanto por Grecia ${ }^{1}$, como por Roma ${ }^{2}$, e incluso el cine biblico tiene ahora un nuevo resurgir. ¿Cómo valora esta recuperación del mundo antiguo en el cine?

AP: Se ha escrito que todo lo que sabemos de Roma lo hemos aprendido en el cine de Hollywood; conviene recordar las relaciones simbólica de los primeros presidentes con el pasado romano idealizando la República (Senado, Capitolio etc.). A las producciones norteamericanas yo añadiría sobre las italianas que desde principios del siglo pasado relacionó su identidad con la historia romana e incluso el propio Vaticano contribuyó a reforzar su protagonismo con el recuerdo exagerado del papel del cristianismo en la antigua Roma.

Con relación a los actuales guiones, hay que tener en cuenta el siguiente axioma: el cine se reproduce a sí mismo. Los productores han visto que esas películas eran comerciales y por ello el género ha vuelto, pero la pregunta más importante es ¿̇cuáles son los guiones? ¿por qué son tan violentas? La respuesta sigue siendo la comercial y llevaría muchas páginas explicar estos temas.

FdP: Sin necesidad de que haya que exigir un excesivo rigor histórico, que no es necesario para contar una buena historia (con minúscula), lo cierto es que el mundo antiguo es completamente irreconocible en muchas de estas superproducciones, pareciendo haber, no sé si estará de acuerdo, una completa despreocupación por hacer verosímil la ambientación ¿Cómo se ha pasado del Espartaco de Kubrick a la serie Spartacus de la cadena Starz, de El León de Esparta a 300 y su secuela, o de Furia de Titanes (1981) a la versión de 2010 y su secuela? ¿Puede ser el cine actual reflejo de un olvido por parte de la sociedad de la cultura clásica?

AP: El tema no es nuevo, el Espartaco de Kubrick es tendencioso, el guión original fue cambiado y se le convirtió en un cristo laico con todas sus consecuencias sociales negativas para el presente. Las otras películas al menos no engañan y obedecen a las nuevas modas dirigidas a las masas mientras consumen palomitas. La cultura clásica no importa mucho hoy día, por ejemplo la democracia ateniense casi no aparece en la pantalla y cuando lo hace es para criticarla frente al modelo espartano.

1 Con superproducciones como Troya (2004), Alejandro Magno (2004), 300 (2006), Ágora (2009), Furia de Titanes (2010), Inmortals (2011), Ira de Titanes (2012), 300: El origen de un imperio (2014), Hércules. El origen de la leyenda (2014).

2 Con películas muy similares como El Rey Arturo (2004), La Última Legión (2007), Centurión (2010), La Legión del Águila (2011), así como las diferentes películas sobre Asterix

3 Mel Gibson abrió el camino con La Pasión de Cristo (2004); recientemente se han estrenado Hijo de Dios (2014), de Christopher Spencer o Noé (2014) de Darren Aronofsky, y en breve aparecerá Éxodo: Dioses y Reyes, de Ridley Scott (2014). También están anunciadas otras cono La Redención de Cain, dirigida y producida por Will Smith, o María (2015) dirigida por Alister Grierson, o una película sobre Poncio Pilatos, que será interpretado por Brad Pitt. 
FdP: El conocimiento del pasado es fundamental para comprender el presente y sus injusticias y por tanto para la construcción de un futuro más justo, pero su manipulación puede favorecer la legitimación de las diferentes formas de poder y la interiorización de la dependencia. ¿Qué papel cree que juegan o deberian jugar los historiadores ante este tipo de manipulaciones interesadas de la historia?

AP: Ese sería el objetivo y es lo que yo intento exponer en mis trabajos, no solo en los de cine, sino en otros en los critico a los que intentan descalificar trabajos importantes bajo la excusa de que «son viejos» o esos temas no interesan hoy día como, por ejemplo, la historia social o «los imperialismos antiguos», aspectos muy importantes para relacionar el pasado con el dramático presente en el vivimos.

FdP: Recientemente han aparecido en los medios de comunicación polémicas sobre algunos temas históricos, como por ejemplo algunas entradas del diccionario biográfico de la Real Academia de la Historia o el simposio celebrado en su universidad con el impactante título "España contra Cataluña». Parece que la Historia interesa a los medios solo cuando entran en cuestión temas políticos cercanos, ¿cree que este tipo de polémicas puede contribuir a que la sociedad tenga una visión de que en Historia "todo es opinable» o que "todo vale»? ¿Qué papel deberiamos jugar los historiadores en relación a los medios de comunicación de masas?

AP: La Academia de la Historia es un centro en el que predomina historiadores de una ideología conservadora y ello facilitó que un medievalista y ministro con Franco escribiera precisamente su biografía de este. El simposio España contra Cataluña no se realizó en mi universidad ${ }^{4}$ y creo que se debería leer detenidamente la conferencia de Fontana que se puede encontrar en internet ${ }^{5}$ y después opinar. Además recomiendo repasar la historia de la llamada «inmaculada transición» para observar cómo de un Estado federal formado por las nacionalidades que entonces se llamaban históricas se pasó a un café para todos con la creación de las actuales Comunidades Autónomas. Un buen ejercicio histórico sería simplemente repasar las hemerotecas, es decir, comprobar la información.

FdP: El fallecimiento de Adolfo Suárez, impulsor de la Transición, ha coincidido en el tiempo con los disturbios producidos el 22M entre las fuerzas de seguridad del estado y los

4 El Simposio «Espanya contra Catalunya: una mirada històrica (1714-2014)» se celebró los días 12-14 de diciembre de 2013, siendo organizado por el Centre d'Història Contemporània de Catalunya (Departament de la Presidència, Generalitat de Catañunya) y la Societat Catalana d'Estudis Històrics (Institut d'Estudis Catalans).

5 La versión castellana, FonTANA, Josep, «España y Cataluña: trescientos años de historia», conferencia inaugural del simposio Espanya contra Catalunya: una mirada històrica (1714-2014), Barcelona, 12 de diciembre de 2013 (traducción de Àngel Ferrero) está disponible en la web <http:// www.sinpermiso.info/articulos/ficheros/fontana.pdf>. 
manifestantes de las marchas por la dignidad, que reclaman una regeneración democrática y de derechos. Si, como decía Gramsci, la crisis se produce cuando lo viejo no acaba de morir y lo nuevo no acaba de nacer, ¿cree que sería necesaria una revisión de los pactos alcanzados tras la muerte del dictador? Y en este sentido ¿Por qué desde el poder político, teóricamente democrático, se tiene tanto reparo ante los referéndums y las iniciativas populares?

AP: Pienso que no se ha alcanzado una verdadera democracia porque no ha habido una ruptura democrática autentica y los aparatos de poder franquista siguen presentes mientras que los intentos de establecer una Memoria histórica de la Dictadura han sido frenados. Estamos en una época en la que el capital financiero domina con el apoyo, en el caso español, de los principales partidos cuyos dirigentes se aferran a sus cargos y sirven a sus señores, es decir, a quienes los han corrompido e impiden que la mayoría de los corruptores y corruptos sean juzgados.

FdP: El sistema educativo público está sufriendo severos recortes en casi todos los ámbitos, que van desde la desaparición de la asignatura de música en primaria, por poner un ejemplo, a la supresión de grados en diferentes universidades, especialmente de humanidades y ciencias sociales, todo ello unido al encarecimiento de las tasas en los estudios superiores y el recorte severo de las becas. ¿Cómo puede esto afectar a la equidad social? ¿Podría la crisis económica legitimar ciertas reformas de carácter ideológico que sería difícil emprender en un estado de bonanza?

AP: Todo ello solo se explica desde las privatizaciones. Los colegios y universidades privadas es lo que importa a los especuladores, con lo que el proceso irá a más. El poder no lo tienen los políticos, sino los especuladores y como he comentado antes es difícil vencerlos, pero no imposible, o al menos hay que mantener la esperanza de que se puede conseguir establecer un mundo mejor. Hay que recordar que en otros momentos fue posible, como recordó el director inglés Loach en El espiritu del 45.

FdP: Una de las consecuencias de la actual crisis es un agravamiento de la precariedad laboral entre los jóvenes, que se ven obligados a trabajar con contratos en prácticas o en formación y con becas que encubren puestos de trabajo por un "sueldo" muy inferior al salario mínimo, ya de por si reducido. ¿Cree que esta forma de precarización podría entenderse en términos de nuevas relaciones de dependencia?

AP: Por supuesto, hay trabajos muy interesantes que describen precisamente al precariado como una nueva clase social.

FdP: Finalmente, y tras agradecerle nuevamente su colaboración, ¿qué consejos les daria a un joven que comience el Grado de Historia?, ¿y a un recién graduado?

AP: En primer lugar, que no se fie de lo que lee y compruebe las fuentes. A partir de ello, que al modo de los sofistas atenienses que busque las explicaciones históricas que 
le parezcan más convincente y siempre tenga claro que se trata de una teoría que puede ser refutada con argumento más sólidos, pero que tenga cuidado con las críticas, ya que muchas de ellas posiblemente no se basen en fuentes sólidas. Por últimos, que los temas que elija interesen a su presente y ayuden a mejorar dicho presente. Por ejemplo, analizar las formas de dependencias antiguas puede ayudar a que los dependientes actuales sepan que en el pasado se crearon otras formas de control social que estaban destinadas a obtener el máximo beneficio de su trabajo y no les interesaba demasiado la situación social de sus trabajadores. 